\section{Transoesophageal echocardiography detects residual ductal flow during video- assisted thoracoscopic patent ductus arteriosus interruption}

\begin{abstract}
This report describes transoesophageal echocardiographic (TEE) monitoring in a one-year-old boy undergoing patent ductus arteriosus (PDA) interruption. After application of a first vascular clip, echocardiographic monitoring detected incomplete interruption of ductal flow, prompting the surgeon to add a second clip to the ductus. The procedure was performed via a new surgical technique: video-assisted thoracoscopic surgery (VATS). This innovative approach offers many advantages to patient care including reduced postoperative pain and better preservation of puimonary function. We conclude that the use of TEE monitoring during PDA interruption via the VATS procedure may improve the surgical result, and eliminate reintervention and the complications associated with residual ductal flow.
\end{abstract}

Nous décrivons l'utilisation de l'échocardiographie transoesophagienne (ETO) comme instrument de monitorage chez un enjant d'un an opéré pour fermeture de canal antériel. Léchocardiographie nous a permis de démontrer la persistance de flux à travers le du canal après l'application d'un premier clip vasculaire. Le chirurgien a alors appliqué un second clip et

\section{Key words}

SURGERY: cardiovascular, thoracoscopy;

ANAESTHESIA: cardiovascular, paediatric; MONITORING: transoesophageal echocardiography.

From the Departments of Anesthesia, Division of Cardiac Anesthesia, Cardiology and Cardiac Surgery, Children's Hospital and Harvard Medical School, Boston, Massachusetts, 02115 .

Address correspondence to: Dr. Joseph J. Javorski, Anesthesia Department, Cardiac Anesthesia Service, Children's Hospital, 300 Longwood Avenue, Boston, Massachusetts, 02115.

Accepted for publication 20 h December, 1993.
Josée Lavoie MD FRCPC, Frederick A. Burrows MD FRCPC, Thomas L. Gentles MB ChB FRACP, Stephen P. Sanders MD, Redmond P. Burke MD, Joseph J. Javorski MD a réussi à abolir tou flux résiduel. Lintervention fut accomplie grâce à une nuuvelle technique chirurgicale: ta chirurgie thoracoscopique assistée par vidéo. Cette nouvelle approche offre phusieurs avantages au patient: la douleur postopératoire est moindre et les fonctions respiratoires sont très peu perturbées. Nous concluons que le monitorage par ETO durant la fermeture thoracoscopique du canal artériel persistant peut améliorer les résultats chinurgicaux, prévenir une réintervention et éliminer les complications associées à la persistance du canal artériel.

Transoesophageal echocardiography (TEE) is being utilized with increasing frequency in the operating roorh both as a monitor and as a diagnostic tool. Although TEE is seldom used to diagnose patent ductus arteriosus (PDA) the specificity and sensitivity of its transthoracic counterpart in diagnosing PDA are well described. ${ }^{1-4}$ Colour-flow mapping and Doppler technology have facilitated the diagnosis and follow-up of PDA. Patent ductus arteriosus diagnosis is also possible with $\mathrm{TEE}^{5}$ but its use as a monitor to ascertain complete ductal interruption intraoperatively has not been described previously.

Video-assisted thoracoscopic surgery has emerged as an innovative new approach to various surgical procedures, including PDA interruption. However, assessing the efficacy of surgical closure by palpating the duct is impossible through diminutive thoracoscopic windows. We report the use of intraoperative TEE to demonstrate the complete interruption of ductal flow in real time during a video-assisted PDA procedure.

\section{Case report}

A one-year-old, $10 \mathrm{~kg}$ boy was admitted to Children's Hospital for video-assisted thoracoscopic PDA interrup- 
tion. The patient was asymptomatic and the past medical history and physical examination were remarkable only for the presence of a restrictive PDA.

The patient was taken to the operating room without premedication and monitored with a five-lead ECG, noninvasive arterial blood pressure, and pulse oximetry. Following preoxygenation and induction of general anaesthesia, a $4.0 \mathrm{~mm}$ ID endotracheal tube was placed through the right nostril and into the patient's trachea. Endotracheal tube position was confirmed by the presence of bilateral breath sounds and an end tidal $\mathrm{CO}_{2}$ waveform on capnography. A leak around the endotracheal tube was audible at $15 \mathrm{~cm} \mathrm{H}_{2} \mathrm{O}$ airway pressure. Anaesthesia was induced and maintained with fentanyl, pancuronium, isoflurane and oxygen. A 22-gauge catheter was placed in the right radial artery and an orogastric tube was inserted to evacuate the stomach. The patient was then placed in the right lateral decubitus position, and prepared for surgery. He tolerated the induction of anaesthesia and repositioning without haemodynamic changes or oxygen desaturation. A HewlettPackard paediatric biplane colour Doppler TEE probe was easily inserted. The paediatric probe has a frequency of $7.5 \mathrm{mHz}$ and each transducer contains 64 elements. Care was taken to protect the endotracheal tube during placement of the probe and the airway was reassessed. The initial intraoperative TEE evaluation revealed normal cardiac anatomy and function except for the presence of a small PDA. Colour-flow mapping demonstrated leftto-right shunting across the PDA. Both horizontal and vertical planes were used to image the ductus arteriosus although, in this case, imaging in the vertical plane allowed better visualization of the PDA in its entirety.

Four $4 \mathrm{~mm}$ thoracostomies were made for insertion of the videoscope, the dissection instrumentation, a lung retractor and the clip applier. Dissection of the descending aorta and aortic arch proceeded to define and expose clearly the underlying patent ductus arteriosus. The recurrent laryngeal nerve was identified and preserved Preparations for rapid volume infusion and immediate thoracotomy were made prior to closing the clip in the event of bleeding from the duct. The patent ductus was then interrupted with a single vascular clip.

Transoesophageal echocardiography imaging and colour-flow mapping revealed residual flow across the ductus (Figure 1, left frame and Figure 2) prompting the surgeon to perform further dissection and add a second vascular clip to the duct. The additional clip abolished all residual flow across the ductus as confirmed by TEE (Figure 1, right frame).

\section{Discussion}

The intraoperative use of transoesophageal echocardio-

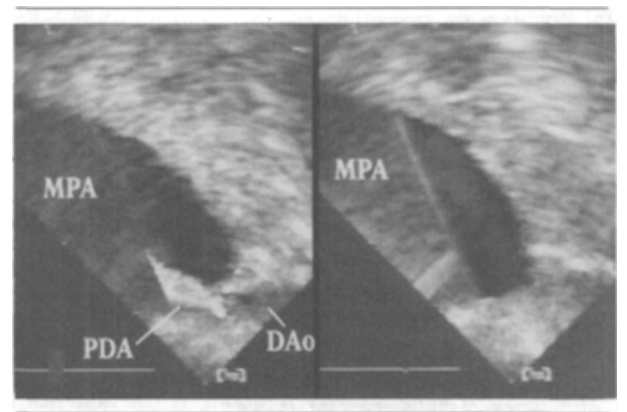

FIGURE I Both frames show a vertical (longitudinal) view of TEE imaging of the patent ductus arteriosus. Left frame: transoesophagea] inaging demonstrates residual flow across the ductus artcriosus following application of first vascular clip. Right frame: demonstrates absence of flow after application of the second clip. $D A O$ : Descending aorta. MPA: main pulmonary artery. PDA: patent ductus arteriosus.

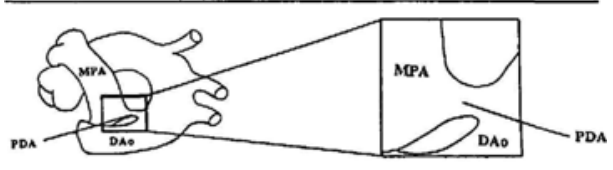

FIGURE 2 Representation of the anatomic orientation of the vertical TEE image illustrated in Figure $I$. The expanded view corresponds to Figure 1, left frame. DAO: Descending aorta. MPA: main pulmonary artery. PDA: patent ductus arteriosus.

graphy is expanding rapidly in cardiac operating suites and is becoming a useful addition to standard monitoring techniques. Transthoracic echocardiography with colourflow mapping allows more sensitive and specific diagnosis of PDA and of residual flow than clinical evaluation alone. ${ }^{6}$ The intraoperative use of TEE is an extension of its transthoracic counterpart allowing real-time evaluation of ductal flow during the VATS procedure and detection of residual flow after ligation.

Video-assisted thoracic surgery is an innovation although it stems from thoracoscopy, a technique first introduced by Jacobaeus in $1910 .^{7}$ The development of video technology and its incorporation into endoscopic methods as well as the creation of adapted instrumentation have given rise to VATS. The technique offers definite advantages to patient care including: reduced postoperative pain, shorter hospitalization, enhanced recovery times and better preservation of pulmonary function. ${ }^{8-9}$ This unique profile makes the procedure an attractive alternative, sparing the patient a rib spreading and muscle tearing manceuvre that may degenerate into a post- 
thoracotomy syndrome characterized by rib fusion, scoliosis, chest wall deformities and compromise of pulmonary function. ${ }^{10-13}$

Although TEE and VATS are accepted techniques in cardiac surgery, they are not without complication. Laryngeal and oesophageal damage have been known to occur with placement of the transoesophageal probe in adults. ${ }^{14}$ In children, arrhythmias have been reported as have isolated cases of bronchial and vascular obstruction. ${ }^{15-17}$ These complications occur infrequently and usually disappear with reduced anteflexion of the probe or by its removal.

Echocardiographic findings of residual ductal flow have been reported to be as high as 23\% after PDA ligation via thoracotomy. ${ }^{6}$ The incidence of residual ductal flow after a VATS procedure is reported to be $5.3 \%$ according to data taken from a single study of 38 patients. ${ }^{8}$ Clinical consequences of residual patency. include haemodynamically significant left-to-right shunting that may result in congestive heart failure and pulmonary oedema, the continued need for antibiotic prophylaxis against subacute bacterial endocarditis and perhaps even reintervention. Furthermore high-flow velocity, as seen with residual patency, is associated with an increased risk of endocardiis. ${ }^{18}$

The sensitivity and specificity of transthoracic echocardiography (TTE) in diagnosing PDA are well established. However, the use of TTE intraoperatively has several disadvantages. The probe is cumbersome and may become a hindrance during the procedure as four thoracostomies are used to manipulate and dissect the anatomical structures. On a small child, these thoracostomies along with the inserted instrumentation do not leave sufficient room for the TTE probe. The probe may also compromise the sterility of the surgical field. Furthermore, the chest cavity is filled with air, as the ipsilateral lung is retracted, and this medium has little echogenicity. Thus intraoperative TTE imaging may be of lesser quality than the preoperative evaluation. Considering these restrictions, intraoperative TEE yields better results than TTE.

With good technique, intraoperative TEE can be a safe diagnostic tool during cardiac surgery. By demonstrating complete ductal interruption in the operating room, the incidence of residual patency may be minimized. This case report demonstrates that TEE monitoring during PDA interruption may improve the surgical result, eliminate reintervention and the complications associated with residual ductal flow.

\section{References}

I Sahn DJ, Allen HD. Real-time cross-sectional echocardiographic imaging and measurement of the patent ductus ar- teriosus in infants and children. Circulation 1978; 58: 343-54.

2 Stevenson JG, Kawabori I, Guntheroth WG. Pulsed Doppler echocardiographic diagnosis of patent ductus arteriosus: sensitivity, specificity, limitations, and technical features. Cathet Cardiovasc Diagn 1980; 6: 255-63.

3 Swensson RE, Valdes-Cruz LM, Sahn DJ, et al. Real-time Doppler color flow mapping for detection of patent ductus arteriosus. J Am Coll Candiol 1986; 8: 1105-12.

4 Liao PK, Su WJ, Hung JS. Doppler echocardiographic flow characteristics of isolated patent ductus arteriosus: better delineation by Doppler color flow mapping. J Am Coll Cardiol 1988; 12: 1285-9].

5 Takenaka $K$, Sakamoto $T$, Shiota $T$, Amano $W$, Jgarashi $T$, Sugimoto T. Diagnosis of patent ductus arteriosus in adults by biplane transesophageal color Doppler flow mapping. Am J Cardiol 1991; 68: 691-3.

6 Serensen KE, Kristensen $B Q$, Hansen $O K$. Frequency of occurrence of residual ductal flow after surgical ligation by color-flow mapping. Am J Cardiol 1991; 67: 653-4.

7 Jacobaeus HC. Possibility of the use of cystoscope for investigation of serous cavities. Munchener Medizinische Wochenschrift 1910; 7: 2090-2.

8 Laborde F, Noirhomme P. Karam J, Batisse A, Bourel P, Saint-Maurice $O$. A new video-assisted thoracoscopic surgical technique for internuption of patent ductus arteriosus in infants and children. J Thorac Cardiovasc Surg 1993; 105: $278-80$.

9 Hazelrigg SR, Landreneau RJ, Boley TM, et al. The effect of muscle-sparing versus standard posterolateral thoracotomy on pulmonary function, muscle strength, and postoperative pain. J Thorac Cardiovasc Surg 1991; 101: 394-401.

10 Van Biezen FC, Bakx PA, De Villenetue VH, Hop WC. Scoliosis in children after thoracotomy for aortic coarctation. J Bone Joint Surg Am 1993; 75: 514-8.

11 Westfelt $J N$, Nordwall $A$. Thoracotomy and scoliosis. Spine 1991; 16: 1124-5.

12 Jaureguizar E, Vazquez J, Murcia J, Diez Pardo JA. Morbid musculoskeletal sequelae of thoracotomy for tracheoesophageal fistula. J Pediatr Surg 1985; 20: 511-4.

13 Gilsanz V, Boechat IM, Bimberg FA, King JD. Scoliosis after thoracotomy for esophageal atresia. AJR Am J Roentgenol 1983; 141: 457-60.

14 Seward $J B$, Khandheria $B K, O h J K$, et al. Transesophageal echocardiography: technique, anatomic correlations, implementation, and clinical applications. Mayo Clin Proc 1988; 63: 649-80.

15 Muhiudeen $I A$, Roberson DA, Silverman NH, Haas GS, Turley $K$, Cahalan $M K$. Intraoperative echocandiography for evaluation of congenital heart defects in infants and children. Anesthesiology 1992; 76; 165-72.

16 Gilbert TB, Panico FG, McGill WA, Martin GR, Halley 
$D G$, Sell JE. Bronchial obstruction by transesophageal echocardiography probe in a pediatric cardiac patient. Anesth Analg 1992; 74: 156-8.

17 Lunn RJ, Oliver WC Jr, Hagler DJ, Danielson GK, Aortic compression by transesophageal echocardiographic probe in infants and children undergoing cardiac surgery. Anesthesiology 1992; 77: 587-90.

18 Rodbard $S$. Blood velocity and endocarditis. Circulation 1963; 27: 18-28. 